\title{
Estimating Households' Maximum Willingness to Pay for Improved Solid Waste Management Services: In Case of Batu Town Administration: Oromia, Ethiopia
}

\author{
Beyene Ibsa Dadi ${ }^{1,2}$ \\ ${ }^{1}$ School of Business and Economics, Oromia State University, Batu, Ethiopia \\ ${ }^{2}$ Economics Department, Oromia State University, Batu, Ethiopia
}

Email address:

beyeneibsa@ymail.com

\section{To cite this article:}

Beyene Ibsa Dadi. Estimating Households' Maximum Willingness to Pay for Improved Solid Waste Management Services: In Case of Batu Town Administration: Oromia, Ethiopia. International Journal of Economy, Energy and Environment. Vol. 5, No. 5, 2020 , pp. 74-82. doi: $10.11648 /$ j.ijeee.20200505.12

Received: January 8, 2020; Accepted: February 26, 2020; Published: September 25, 2020

\begin{abstract}
This study is initiated by the current deep rooted problem of improved solid waste management services supply prevailing in Batu town and its primary objective is to estimate maximum willingness to pay of households' using contingent valuation method. A total of 229 sampled households were interviewed in person. A single bounded closed ended followed by open-ended format were used to elicit willingness to pay for improved solid waste management services. Of 229 respondents $205(89.52 \%)$ accepted bid values of improved solid waste management services provided to them. The data was analyzed both in descriptive and econometric models. The tobit model was used for empirical analyses. Households' maximum willingness to pay for one sack of improved solid waste management services was 14.01 birr in open ended format. Households characteristics' such as sex, income, occupation and education are positively determine the probability of accepting the given bid value of improved solid waste management services. The bid value and age of the respondent negatively affect the maximum willingness to pay for improved solid waste management services in tobit model. The study revealed that households are willing to pay more than of the current rate of 5 birr in average per one sack solid waste collection service. Therefore if the improvement scenario comes to effect in one way it solves the shortage of improved solid waste management services problems in the other way the town's solid waste management office can collect more revenue from service charge.
\end{abstract}

Keywords: Willingness to Pay, Contingent Valuation, Solid Waste

\section{Introduction}

Solid Waste is anything that is neither liquid not gas and is discarded as unwanted [1]. It includes any garbage, refuse, sludge from a waste treatment plant, water supply treatment plant, or air pollution control facility and other discarded material, including solid, semisolid, or contained gaseous material resulting from industrial, commercial, mining, and agricultural operations, and from community activities. Poorly managed solid waste is the cause for various diseases and contributes to global warming.

Solid waste management requires huge financial resources, which sometimes beyond the capacity of urban municipalities. High population growth and the change in human economic activities contribute to high solid waste generation in urban centers. Nowadays per capita solid waste generation increases in urban centers which are among urban problems deteriorating the quality of cities. Most of the time urban municipality could not able to solve this problem due to the lack of financial resources.

Solid waste management in Batu town had been undertaken by the city municipality and some solid waste collectors associations. The management of solid waste involves storage at the source (primary storage or secondary storage), collection, transportation and final disposal of the waste. There is no one best mechanism of managing solid waste that can serve best all cities. One has to approach managing solid waste in an innovative manner since selection of the best device and practice at each stage depends on a variety of specific circumstances to the city under consideration. 
Batu town administration is one of towns in Oromia regional state found in the Great Rift Valley with poor solid waste management system. Poor solid waste management can adversely affect the health of residents. To improve this problem the town's administrations together with all stakeholders need to improve the system. The existing solid waste collection service charge should be revised through cost recovery method based on the affordability of the residents. Therefore, demand side study is required to know the willingness to pay of households for improved solid waste management service and choose appropriate service charge structure. One way of measuring non market environmental goods such as solid waste management is through collecting and analyzing information on willingness to pay of users for change in quality or quantity of these goods based on their stated preference.

Contingent valuation method is one technique of elicitation of willingness to pay in which we can create hypothetical market for non-market environmental goods in order to collect responses of households on how much they are willing to pay for improvements. It is a technique of putting monetary values on non-market goods depending on the hypothetical market/contingency. It can capture both use and none use values of environmental amenities. This method has being used to value environmental goods of with no actual market price starting from its development in 1947 [2].

The purpose of this paper is to estimate the maximum willingness to pay of households for improved solid waste management service through introducing hypothetical market with CV household surveys.

\subsection{Statement of the Problem}

Enhancing improved solid waste management services to the fast growing urban population assists poverty reduction programs through improving the health of productive group of society. Promoting the participation of beneficiaries in maintenance and expansion of urban utilities provision is important as it increases the material as well as financial capacity of utility providers. Batu town administration municipality service couldn't meet the solid waste collection services which covers all population of the town.

The provision of improved solid waste management is mostly fueled by an increase in urban population and shortage of finance [3]. To fill the gap and improve service sustainability the demand responsiveness approach is important. The revenue being collected from the existing services is inadequate to begin new projects according to Batu town municipality office.

Currently, there is no modern container loading vehicles. The town administration is using two tractors to transport some solid waste to the land fill. The existing land fill itself is very old and narrow in space to capture the collected solid wastes. There are only six containers used to store solid wastes temporary until transported to the land fill. Private associations giving solid waste collection services are unevenly distributed in the town and only limited to the areas close to the center or main road particularly around business areas. Majority part of the solid waste generated by residents and business centers is dumped to the dembel lake with flood occurring during rainy seasons, which adversely affect the fish resource.

Therefore, in order to improve the solid waste management service level in both quantity and quality the office should expand private solid waste collectors, revise the service charge structure and conduct expansion projects to adjust it with growing demand. This can realized through awareness creation and ensuring residents participation in those projects based on capacity and willingness to pay of households. The paper tries to estimate the maximum willingness to pay for improved solid waste management services and the factors that determine the maximum willingness to pay which is supposed to be an input for the city's utility planners and decision makers.

\subsection{Research Questions}

1) What is the maximum amount of birr that households are willing to contribute for the better access to solid waste management service?

2) What factors affect households' maximum willingness to pay?

3) What is the aggregate amount that households' are willing to pay?

\subsection{Objective of the study}

The general objective this paper is to estimate the maximum value of willingness to pay of households' for improved solid waste management services using contingent valuation survey method.

Specific Objectives

1) To estimate the maximum willingness to pay for improved solid waste management services.

2) Determine factors affect households' maximum willingness to pay.

3) Aggregating the maximum willingness to pay.

\section{Methodology}

\subsection{Research Design}

Research design is required to facilitate the smooth operation of any research process making research efficient and effective [4]. The research design to be employed in this study is descriptive and explanatory which best answers the questions raised and meet predetermined objective. Descriptive research describes the characteristics of individuals, groups and situation in relation to something. The nature of this study is based on the analysis of the existing phenomenon and deriving at some conclusions. The existing solid waste management situation is analyzed, the solid waste removal practices of households and their willingness to pay is calculated based on the survey responses. In addition to these factors determining willingness to pay for improvement scenario is identified through drawing relationships. This makes the design share explanatory characteristics. 


\subsection{Data Type and Sources}

This paper primarily used primary data collected from the sample of households' from each kebeles of the town. In addition to this secondary data from different reliable source was used. Structured questionnaires' was prepared to collect the primary data according to contingent valuation survey method. Random sample technique system was employed to draw sample of households.

\subsection{Sample Size}

As recommended in theoretical part of this study simple random sampling is appropriate sampling technique to have equal chance of including each household in the sample. A proportional sample of households was obtained using a simple random sampling technique from a list of each kebeles' households. A total of 229 sample respondents were selected proportionally to the size of total households in each kebele.

The sample size was determined according to Kothari (2009) formula.

$$
\mathrm{n}=\frac{z^{2} \text { p.q. } \mathrm{N}}{e^{2}(\mathrm{~N}-1)+z^{2} \text { p.q. } \mathrm{N}}
$$

Where $\mathrm{n}=$ Sample size

$\mathrm{z}=$ the value of standard variate at the given confidence interval (usually set at $95 \%$ confidence level)

$\mathrm{P}=$ population proportion

$\mathrm{e}=$ margin of error

Accordingly, the total household size of the town is $\mathrm{N}=7600$

Confidence interval of $95 \%(\mathrm{z})=1.96$

Population proportion to be included in the sample taken from pretest response rate $(\mathrm{p})=81 \%=0.81 \mathrm{q}=1-\mathrm{p}=1-0.81=0.19$ or $19 \%$

Margin of error $(e)=0.05$ therefore the sample size is calculated as:

$$
\mathrm{n}=\frac{(1.96)^{2}(0.81)(.19)(7600)}{(0.05)^{2}(7600-1)+(1.96)^{2}(0.84)(0.19)}=229
$$

Therefore, the study takes a sample of 229 households

\subsection{Methods of Data Analysis}

Data analyses were carried out in both descriptive as well as using econometrics models. The, minimum and maximum values socio-economic and demographic status of respondents was calculated and presented in the form of tables and graphs. The STATA 11.1 version software was employed in identifying factors affecting responses and respondents maximum willingness to pay for improved solid waste management service.

\subsection{Model Specifications}

The Tobit Model

Tobit model (censored regression) is appropriate model when dependent variable is continuous but constrained in some ranges [5]. The model is used when some values of dependent variable is non-negative zero and the other part is different outcomes. When data are censored the appropriate distribution of the model is the mixture of discrete and continuous distribution [6].

Following the general formulation of tobit model in Green (2011)

$$
\mathrm{Y}_{\mathrm{i}}^{*}=\mathrm{X}^{\prime} \beta+\varepsilon_{\mathrm{i}}
$$

$\mathrm{Y}_{\mathrm{i}}=$ is dependent variable it can be willingness to pay or not to pay

$\mathrm{X}^{\prime}=$ explanatory variable

$\varepsilon_{\mathrm{i}}=$ Normally distributed stochastic random variable with $\mu$ and constant variance $\sigma^{2}$.

Assume that there is perceived utility (U) for paying for improved solid waste management service.

$\mathrm{U}_{\mathrm{i}}=1$ if $\mathrm{U}_{\mathrm{i}}^{*}>0$ paying for an improved solid waste management service

$\mathrm{U}_{\mathrm{i}}=0$ if $\mathrm{U}_{\mathrm{i}}^{*}<0$ for not paying

$\mathrm{U}_{\mathrm{i}}^{*}$ is unobserved latent variable or the threshold, observed only if WTP is non-negative number greater than zero.

The expected value of $U$ is:

$$
\mathrm{E}(\mathrm{U})=\mathrm{X}_{\mathrm{i}} \beta \mathrm{F}(\mathrm{Z})+\delta \mathrm{f}(\mathrm{Z})
$$

Where $\mathrm{X}=$ vector of explanatory variable

$\mathrm{Z}=$ cumulative distribution function

$\mathrm{Z}=\mathrm{is}$ given as $\mathrm{X} \beta / \delta$

$\beta=$ vector of tobit maximum likelihood estimates

$\delta=$ standard error

The of all observation and conditional value above the limit of $\mathrm{U}^{*}$ is of

$$
\mathrm{U}=\mathrm{F}(\mathrm{Z}) \mathrm{U}^{*}
$$

Then the Log likelihood of the tobit model is

$$
\begin{gathered}
\ln L=\sum\left[-\frac{1}{2}(\log (2 \pi))+\ln \delta^{2}+\left(U_{i}-X^{\prime} \beta\right)^{2}\right]+ \\
\sum_{u=0} \frac{\ln \left[1-\emptyset\left(X^{\prime} \beta\right)\right]}{\delta}
\end{gathered}
$$

Maximizing the likelihood function with respect to $\beta$ and $\delta$ will give as the estimation of these parameters. The maximum willingness to pay responses to $\mathrm{CV}$ questions was regressed against the households' socio-economic characteristics and solid waste management service attributes.

Thus, the tobit model for maximum willingness to pay to be estimated in this study has the form of:

$$
\mathrm{U}_{\mathrm{i}}=\mathrm{MWTP} * \text { if MWTP } *>0,=0 \text { if } \mathrm{MWTP} \leq 0=0
$$

Here the vector maximum willingness to pay for improved solid waste management service was censored from the left at zero, as some responses contain true zero willingness to pay. This s we can only see the maximum amount to pay if the response is greater than zero value.

Model to be estimated in this research paper is $\mathrm{U}_{\mathrm{i}}=\mathrm{MWTP}_{\mathrm{i}}=\beta_{0}+\beta_{1}$ gdr $+\beta_{2} \mathrm{mrst}+\beta_{3}$ age $+\beta_{4}$ edu $+\beta_{5}$ ocp $+\beta_{6}$ incm + 


$$
\beta_{7} \mathrm{fms}+\beta_{8} \text { pay }+\beta_{9} \text { sat }++\beta_{10} \text { bidv }+\varepsilon_{\mathrm{i}}
$$

\section{Data Analysis and Discussion of Results}

This section deals with procedures of data analysis and discussion based on the results of survey. The analysis was made in both methods as described in the methodology part. Both descriptive and econometric analyses were done. The socio-economic and demographic status, the existing improved solid waste management services and aggregation of willingness to pay were done descriptively and presented in the form of tables and graphs. Factors affecting the decision of willingness to pay, value of willingness to pay were analyzed using econometric models. Two likelihood estimators of econometrics models were used in the empirical analysis of data separately. The willingness to pay and the factors affecting willingness to pay for improved solid waste management were analyzed from closed ended formats with probit model. The maximum willingness to pay of responses of open ended format and determining factors were analyzed using tobit model. Of 229 responses 24 were true zero, so that censored regression model was used. The analysis of this study was made with the aid of STATA 11 version software.

\subsection{Socio-economic and Demographic Analysis of Respondents}

In this study a total of 229 households were interviewed. Of the sampled households $88(38.04 \%)$ are male and 141 $(61.57 \%)$ are female. The marital status shows that 126 $(55.02 \%)$ respondents are married and $103(44.98 \%)$ are others (Such as single, divorced and widowed). The average age of respondents is 35.29 years of which 15 years is minimum and 90 years is maximum.

Of the total respondents $148(64.63 \%)$ respondents have got formal education and $81(35.37 \%)$ they are illiterate. The occupation status of respondents shows that 128 (55.90\%) are employed in different government, private organizations and different income earning activities. The monthly income of respondents is 1746.751 , with minimum 0 and maximum 10000.00 birr.

Average monthly expenditure of households is 1993.6 birr with the minimum of 100 birr and 8000 birr maximum. The average family sizes of households were about 5.3 with the minimum of 1 to 13 persons.

Of 229 respondents $124(54.15 \%)$ have their own house and $105(45.85 \%)$ have not. The interviewed households were living in the area for 20.02 years in average with the minimum of one year and maximum of sixty years.

\subsection{The Current Solid Waste Collection Services and Households Solid Waste Management Practices}

Currently there are about six associations of different size collecting solid waste in the town. The total capacity of solid waste collection per week is about $625 \mathrm{~m}^{3}$ according to the office 2019 report. The weekly generation per household per week was 1.25 sacks with a minimum of 0.25 sacks and a maximum of 3 sacks. Here, there is no actual measurement of solid waste generation, but respondents were encouraged to estimate the weekly generation in terms of sack. The important point the study wants to emphasize is how the 'estimate' varies across households and how this affects their willingness to pay.

The survey result shows households getting solid waste collection service from the different association paying a monthly amount of up to 5.00 Birr, mainly determined by a type of bargaining with the household head. The average frequency of solid waste collection is 1.5 times a week in most cases.

The solid waste collection service coverage of the town is currently estimated to $48 \%$ according to the office. This implies that large number of household is still waiting for improved solid waste collection services. Of the total 229 households about $117(51.09 \%)$ are unsatisfied with solid waste collection services. The current total revenue being collected from service charges of solid waste provided to households is on average estimated to 38000.00 birr per month.

The primary concern of this paper is to analyze households' solid waste management and their willingness to pay for improvement in services. Respondents were asked whether they are satisfied with the quantity of solid waste collected and $184(80.35 \%)$ responded the service is good and about 45 $(19.65 \%)$ said it is poor. Regarding to the quality in service while collecting solid wastes $146(63.76 \%)$ respondents said the service quality is good and $83(36.44 \%)$ are unsatisfied with the existing service.

\subsection{Households' Willingness to Pay for Improved Solid Waste Management Services}

Of 141 female respondents $205(89.52 \%)$ were willing to accept the improvement bid values. Only 24 (10.48\%) refused the bid. Among 88 male respondents 70 (87.5\%) are willing to pay the bid value and $18(16.5 \%)$ were rejected the improvement. In other way among 126 married respondents $125(99.2 \%)$ of them were positive to pay the provided bid value of improvement, however $1(0.8 \%)$ refused.

Among 148 educated respondents 145 (97.97\%) were willing to pay and only $3(2.03 \%)$ of them refused the price. Moreover, of 128employed respondents 127 (99.2\%) accepted the bid value of improvement. $1(0.8 \%)$ respondents were not willing to pay this price. Among 112 unsatisfied respondents with the current solid waste collection services $99(88.4 \%)$ were willing to pay and only $13(11.6 \%)$ refused the bid value.

In this study five bid values were introduced for improved solid waste management services. These prices were selected during pretest of questionnaires with the open ended question format provided for 35 respondents randomly selected from each kebele. The mode of those values was taken and 5, 10, 15,20 and 30 birr were selected as starting values of improved solid waste management service per a sack of solid waste. A sack is used as unit of measurement because almost 
every household are familiar with this material. These values were randomly distributed to 229 respondents in the equal proportion. From 229 respondents 205 (89.5\%) replied "yes" and $24(10.5 \%)$ respondents said "no" to the initial bid of improved solid management services. The following table summarizes the bid price and corresponding willingness to pay for those prices.

Table 1. Summary of Bid value and Willingness to pay for Initial bid.

\begin{tabular}{llll}
\hline \multirow{2}{*}{ Bid value } & \multicolumn{2}{l}{ Willingness to pay } & \multirow{2}{*}{ Total } \\
\cline { 2 - 3 } & No & Yes & \\
\hline 5 & 0 & 49 & 49 \\
10 & 0 & 36 & 36 \\
15 & 2 & 43 & 45 \\
20 & 4 & 40 & 44 \\
30 & 18 & 37 & 55 \\
Total & 24 & 205 & 229 \\
\hline
\end{tabular}

Source: Survey 2019.

The above table shows that of the five bids provided to respondents 49 accepts 5 birr and no one respondents refuse this amount. Of total respondents provided with 10birr for one sack of solid waste 36 reveal their willingness to pay and no one of respondents rejected. In the same scenario $15 \mathrm{birr}$ was randomly distributed to respondent of which 43 replied yes and 2 didn't accept. For respondents which 20 birr initial bid price was introduced 40 accepted and 4 rejected this value.

Finally, 73 respondents accepted 30 of bid value of improved solid waste management service and 18 rejected this amount. We can see from this as the bid value of improved solid waste management increases the willingness to pay decreases.

Respondents were also provided with open ended question of the maximum willingness to pay for improved solid waste management services. Out of 229 respondents' 210 (91.7\%) gave greater than zero values for improved solid waste management services with a minimum of 1 birr to the maximum of 50 birr per week. About 19 (8.3\%) respondents expressed true zero maximum willingness to pay for improved solid waste management service of which 115 $(50.22 \%)$ said that solid waste should be collected for free, $52(22.71 \%)$ replied that they have no enough money and 62 $(27.02 \%)$ hesitated that the money will be misused, so that the improvement will not be realized depending on his perception of previous broken promises.

Table 2. Summary of Respondent Maximum Willingness to Pay.

\begin{tabular}{lllll}
\hline Bid values & Mid value & Freq & Percent & Cum \\
\hline $0-10$ & 5 & 111 & 48.47 & 48.47 \\
$11-20$ & 15.5 & 78 & 34.06 & 82.53 \\
$21-30$ & 20.5 & 32 & 13.97 & 96.5 \\
$31-40$ & 35.5 & 3 & 1.31 & 97.8 \\
$41-50$ & 45.5 & 5 & 2.2 & 100 \\
\hline
\end{tabular}

Source: Survey 2019.

From the above table we can see that 111 (48.97\%) households are willing to pay about 5birr in average, 78
(34.06\%) willing to pay 15.5 birr, 32 (13.97\%) 20.5 birr, 3 $(1.31 \%)$ willing to pay 35.5 and $5(2.2 \%)$ are willing to pay 45.5 birr for improved solid waste management services in open ended format. The maximum willingness to pay for improved solid waste management services is 14birr per one week.

From the closed ended format the willingness to pay for improved solid waste management service was estimated to 12.86 birr per one sack of solid waste collection. When we compare this amount to what the households are currently paying in average (i.e. 4.5 birr) it is much higher.

\subsection{Determinants of Maximum Willingness to Pay for Solid Waste Management Services}

Before econometrics analysis is done data were checked for existence of severe colleniarities among independent variable and pair wise correlation was run. In this case the researcher used the correlation standard indicated in most literature which is 0.75 for an indication of severe colliniarty. Thus, there is no severe multi-colliniarity among independent variables.

The model specification was also tested using link test to check for the functional form of willingness to pay miss specification. From the result the hat square value is insignificant which $\mathrm{s}$ that the there is no model misspecification. The other issue is the issue of heteroscedasticity problem which is common in crosssectional data analysis.

Regression Analysis

The determinants of households' maximum willingness to pay for improved solid waste management service were analyzed using censored regression of tobit model. Tobit model (censored regression) is appropriate model when dependent variable is continuous but constrained in some ranges [5]. The model is used when some values of dependent variable is non-negative zero and the other part is different outcomes. When data are censored the appropriate distribution of the model is the mixture of discrete and continuous distribution [6]. In this study open-ended CV format was analyzed by tobit model to estimate the maximum amount households are willing to pay for improved solid waste management service. In eliciting maximum willingness to pay through open ended formats some respondents gave true zero maximum willingness to pay for improved solid waste management service. Therefore some values of our dependent variable of maximum willingness to pay (MWTP) are zero. To capture this problem tobit model is appropriate for estimation. From a total of 229 useful responses 19 respondents replied that the maximum amount they willing to pay is true zero. Tobit model is also used to identify factors that determine the maximum amount of money the respondents are willing to pay for improved solid waste management service.

Following the general formulation of tobit model in Green (2011)

As we know from literatures censored regression models are used for non-negative dependent variable with some zero 
values. Estimating parameters using OLS if we have censored dependent variable leads to bias and inconsistency of parameters [6]. Therefore, the maximum willingness to pay for improved solid waste management service is regressed against socio-economic characteristics of respondents and some solid waste management service attributes. The maximum willingness to pay of respondents' is censored at zero from the left. Here MWTP is a latent variable that could be seen if its value is greater than zero $(\mathrm{MWTP}>0)$. The tobit model output from STATA 11 is indicated in the following table.

The output of the regression model shows that Loglikelihood $\mathrm{Chi}^{2}$ which indicates the overall significance of the model is significant. This $\mathrm{s}$ that the null hypothesis of all coefficients are zero is rejected at $1 \%$ significance level which confirms that at least one coefficient is different from zero. In addition to this the pseudo $\mathrm{R}^{2}$ also shows the included independent variables have some explanatory power in the variation of willingness to pay. Therefore the model can fit statistically to infer.

Table 3. Regression result.

\begin{tabular}{|c|c|c|c|c|c|c|}
\hline MWTP & Coef. & Robust std. err & $\mathbf{t}$ & $\mathbf{p}>/ \mathbf{t} /$ & \multicolumn{2}{|c|}{ [95\%] conf. Interval] } \\
\hline $\mathrm{Gdr}$ & -0.2217681 & 1.354074 & -0.17 & 0.867 & -2.895852 & 2.441516 \\
\hline Mrst & 2.782544 & 1.763072 & 1.58 & 0.116 & -0.6922151 & 6.257303 \\
\hline Age & 0.0405719 & 0.049123 & 0.83 & 0.410 & -0.0562424 & 0.1373862 \\
\hline Edu & 5.700217 & 1.605037 & 3.55 & 0.000 & 2.536922 & 8.863512 \\
\hline Incm & 0.0010453 & 0.000374 & 2.79 & 0.006 & 0.0003081 & 0.0017825 \\
\hline Fms & 0.5286135 & 0.257699 & 2.05 & 0.041 & 0.0207261 & 1.036501 \\
\hline Sat & -0.5899936 & 1.506723 & -0.39 & 0.696 & -3.559526 & 2.379539 \\
\hline Ibid & 0.3622283 & 0.1000816 & 3.62 & 0.000 & 0.164982 & 0.5594747 \\
\hline Cons. & -5.835246 & 4.399635 & -1.33 & 0.186 & -14.50629 & 2.835799 \\
\hline /sigma & 9.462149 & 0.5737512 & & & 8.361369 & 10.62293 \\
\hline
\end{tabular}

Number of obs $=229$.

$\mathrm{F}(10,219)=5.46$.

Prob $>\mathrm{F}=0.0000$.

Psedo $\mathrm{R}^{2}=0.0337$

Log pseudo likelihood=-791.14726Obs. summary 19 left censored observations at mwtp $<=0$.

\section{0 uncensored observations}

Education level of respondent is an important variable in the tobit model as it is positive and significant at $1 \%$ significance level. This shows that educated people pay more than people have no any formal education. It may be due to the fact that educated section of the society is more aware of about their health and wish for improvement.

The variable family size has positive relationship with maximum willingness to pay for improved solid waste management service which is significant at 5\% significance level. The direction of influence of this variable is not consistent with prior expectation. As households' family size increases their willingness to pay the maximum amount decreases. This is due to the fact that large family size expected to generate more solid waste management and the chance of paying for cope up increases. The other possible reason is large family size especially with high number of employed adults will increase the probability of paying maximum amount because they can share the family's costs.

The income level of the respondent was also consistent with the prior expectation and statistically significant at $1 \%$ significance level. Those households with higher income pay more for the improvement program. This is consistent with the study conducted by [7].

The amount of bid value provided to the respondents is also a very interesting and statistically significant variable in tobit model. The coefficient on bid value has positive sign and significant at $1 \%$ significance level. The result is again consistent with [8].
Finally the maximum willingness to pay for improved solid waste management service per week from open ended format is simply calculated as dividing the total sum of maximum willingness to pay of respondents to the number of sampled households. Thus the total sum of maximum willingness to pay (MWTP) is 3209 birr.

$$
M W T P=\frac{\sum M W T P_{i}}{n}=\frac{3,209}{229}=14.01 \mathrm{birr}
$$

The maximum willingness to pay per month will be $14.01 * 4=56.05$ birr.

\subsection{Estimation of Total Willingness to Pay and Total Revenue of Improved Solid Waste Collection Services}

Our third research question aimed to be answered by the result of this study was the amount of aggregate willingness to pay of households. Depending on the open ended question of maximum willingness to pay for improved solid waste collection service we estimated the total willingness to pay for improved solid waste collection service. We used open ended responses of maximum willingness to pay to aggregate the total willingness to pay because open ended formats earn more information than closed ended formats and statistically efficient [9]. This is the fact that closed ended formats may suffer from starting point bias and the conclusion derived is required large sample survey. Summarizing a series of maximum willingness to pay to class boundary intervals the aggregated contribution of households was estimated as 
indicated in the following table. Currently, the total are females and $49 \%$ are males. There are about 7600 population of the town is estimated to be 76473 of which $51 \%$ households with the average family size of 5people.

Table 4. Total Willingness to pay and Total revenue From Improved solid waste collection service.

\begin{tabular}{|c|c|c|c|c|c|c|c|c|c|}
\hline \multirow{2}{*}{$\begin{array}{l}\text { Summary } \\
\text { of MWTP } \\
\text { in class } \\
\text { intervals }\end{array}$} & \multirow{2}{*}{$\begin{array}{l}\text { Mid } \\
\text { value/class } \\
\text { mark in } \\
\text { cents }\end{array}$} & \multirow{2}{*}{\multicolumn{2}{|c|}{$\begin{array}{l}\text { Proportion of } \\
\text { sampled hhs in } \\
\text { each interval }\end{array}$}} & \multirow{2}{*}{$\begin{array}{l}\text { Proportion } \\
\text { of } \\
\text { households }\end{array}$} & \multirow{2}{*}{$\begin{array}{l}\text { Total } \\
\text { WTP in } \\
\text { birr }\end{array}$} & \multirow{2}{*}{\multicolumn{2}{|c|}{$\begin{array}{l}\text { Sampled hhs WTP } \\
\text { Minimum amount that } \\
\text { interval }\end{array}$}} & \multirow{2}{*}{$\begin{array}{l}\text { Total hhs WTP } \\
\text { this amount } \\
\text { G=F\%*Total } \\
\text { Hhhs }\end{array}$} & \multirow[t]{2}{*}{$\begin{array}{l}\text { Total Revenue (in } \\
\text { birr) } \mathbf{H}=\mathbf{B}^{*} \mathbf{G}\end{array}$} \\
\hline & & & & & & & & & \\
\hline A & B & $\mathrm{C}$ & $\%$ & D & $\mathbf{E}$ & $\mathbf{F}$ & $\%$ & G & H \\
\hline $0-10$ & 5 & 111 & 48.5 & 3686 & 18430 & 229 & 100 & 7600 & 38000 \\
\hline $10-20$ & 15.5 & 78 & 34.1 & 2591.6 & 40169.8 & 118 & 51.528384 & 3916.157 & 60700.437 \\
\hline $21-30$ & 20.5 & 32 & 13.9 & 1056.4 & 21656.2 & 40 & 17.467249 & 1327.511 & 27213.974 \\
\hline $31-40$ & 35.5 & 3 & 1.3 & 98.8 & 3507.4 & 8 & 3.4934498 & 265.5022 & 9425.3275 \\
\hline $41-50$ & 45.5 & 5 & 2.2 & 167.2 & 7607.6 & 5 & 2.1834061 & 165.9389 & 7550.2183 \\
\hline Total & & 229 & 100 & 7600 & 91371 & & & & \\
\hline
\end{tabular}

Source: Own Survey 2019.

From open ended format we have got maximum willingness to pay for improved solid waste collection service responses ranging from 0 birr to 50 birr per one sack. The values were condensed in the above table using class boundaries simply for convenience. Column A summarizes the maximum willingness to pay of respondents per one sack. Column B is the class mark (mid value) of the interval of maximum willingness to pay. Column $\mathrm{C}$ is number of sampled households whose maximum willingness to pay is categorized in each class boundaries.

Other columns are derived from these three columns. Column D shows total number of households' categorized in each interval of maximum willingness to pay. This is calculated as multiplying the percentage of sampled households categorized in each class boundaries by the total number of households (i.e. total number households in the town). Column $\mathrm{E}$ is total amount of maximum willingness to pay of each category of boundaries. It was calculated as multiplying the mid value of maximum willingness to pay of respondents of each category by the total number of households categorized in each interval. Assuming that a single household produces only one sack per week the total amount of maximum willingness to pay of 7600 households of the town will be 91371 birr. From the survey conducted the average solid waste production capacity of sampled households was estimated to 1.12 sacks per week. If we aggregate this amount to the total households the total willingness to pay for improved solid waste collection service will be 102335.52 birr per week. This gives 56.86 per household per month.

Column $\mathrm{F}$ is the number of sampled households who can pay the minimum amount of birr within a given interval. Column $\mathrm{H}$ is the total revenue that will be collected if the proposed improvement is come to effect. It was calculated as multiplying the mid values of maximum willingness to pay by the total number of households.

From the table we can see that total revenue increases as service charges increases and it reaches maximum of 94245.415birr when per unit price is 15.5 birr and decreased to a minimum of $496.72489 \mathrm{birr}$ when the number of households who accept the higher price decreased to 5 . Total revenue is obtained by multiplying the class mark (mid values) by the total number of households who are willing to accept at least that amount within the interval.

We can graph the last column of the table which depicts the total revenue on the vertical axis and class mark (mid value) on the horizontal axis.

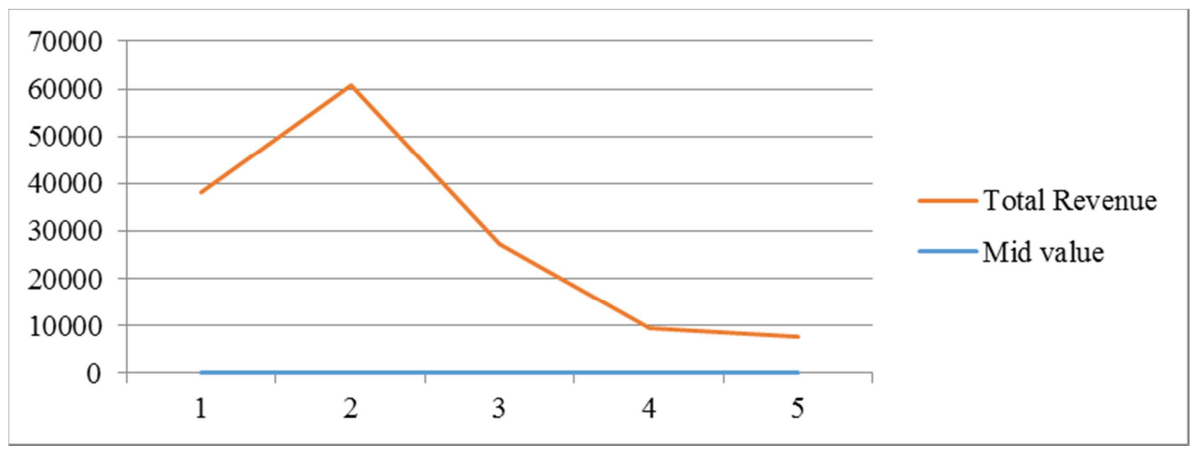

Figure 1. Total Revenue of Improved solid waste collection service per month.

Mid Value of Maximum Willingness to pay.

Source: Own Survey 2019.

Therefore this result implies that if the improvement program is undertaken by the town's municipality it not only improves the solid waste management services but also increases the revenue collected from solid waste collection 
service which enables to sustain the service and expand the provision.

We can also derive the demand curve for improved solid waste collection service of households against the mid value of maximum willingness to pay. As shown below the demand curve of improved solid waste collection service is similar with the nature of other normal goods demand curves. The demand curve of normal good is downward sloping showing that the quantity demanded and price is negatively related. Analogously in this study as the service charge of solid waste collection service increase (the bid value in our case) the demand will fall down. This curve shows that the number of households willing to pay the maximum amount (horizontal axis) and the amounts of bid values in birr (vertical axis).

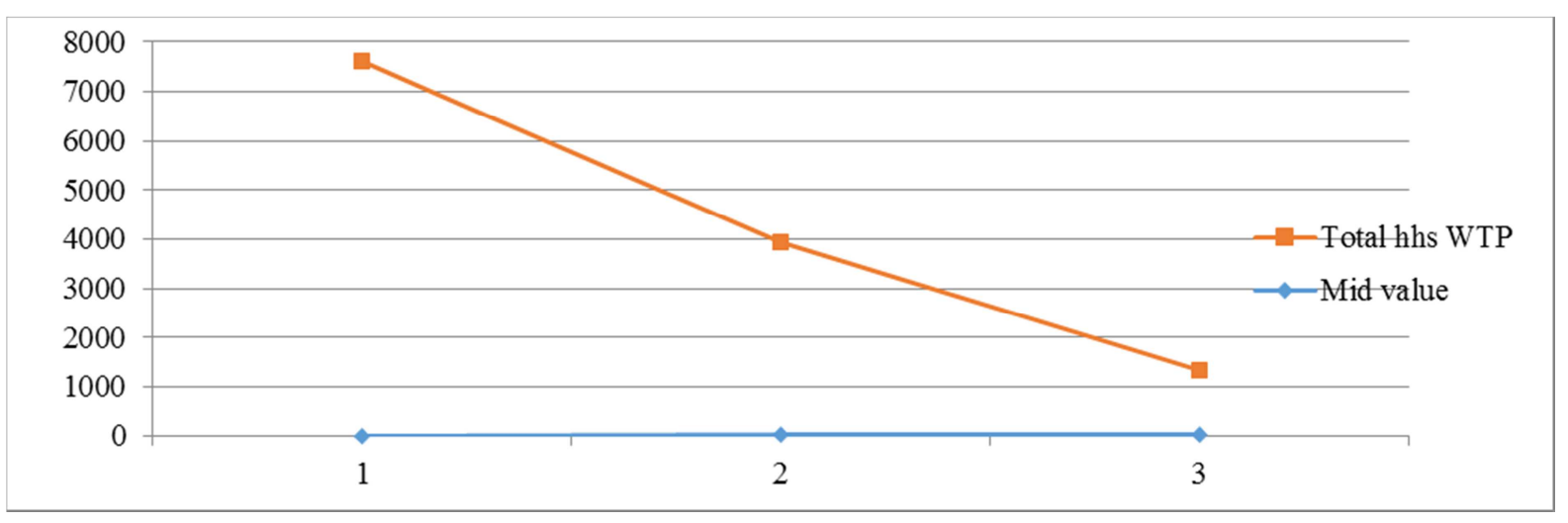

Figure 2. Demand Curve for Improved Solid waste collection service Services.

Mid values (in birr)

Source: Own Survey 2019.

As seen from the above figure the number of households decline as the bid value (price) of improved solid waste collection service increases.

In general we found that the maximum willingness to pay of households of Batu town for improved solid waste management service is 56.05 birr per month from opened ended formats. This amount is by far higher than what the households' are paying which is around 25birrper month for those households in average.

\section{Conclusions and Recommendations}

\subsection{Conclusions}

From the results of this study the researcher found that there is high gap between the demand and supply of improved solid waste management service in the town. Households are willing to pay more than the current service charge if the improvement programs are conducted. The maximum willingness to pay of households of Batu town for improved solid waste collection service is estimated to be 56.05 birr per month. The households' aggregate maximum willingness to pay for improved solid waste management is estimated to 102335.52 birr per month.

Households' characteristics' such income, occupation, house ownership, duration of staying in the town, level of satisfaction with the existing service and education are positively determine the probability of paying high value for improvement scenario. Occupation, education and income positively and significantly affect maximum willingness to pay in tobit model. Bid value has positive sign and significant at $5 \%$ sig. level.

\subsection{Recommendations}

The researcher would like to recommend the following issues depending on the results of the study. The town's municipality should encourage private solid waste collectors, undertake the construction of landfills, purchase additional containers, motorized solid waste collecting vehicles, install dust bins, and enhance residents' awareness, etc. with other stakeholders to meet the required level of service. Intensive demand side study is required in order to arrange cost recovery strategies.

Occupation status and income have positive effect on households' maximum willingness to pay for improved solid waste management services, thus the town's administration should focus on job creation activities especially for youth section of society. Since educated section are more willing to pay than uneducated one, the concerning body should work hard in promoting adult education particularly.

The study indicated that the main shortage of current improved solid waste management services of the town is related to high population growth in the town. Therefore, the office should clearly predict the total number of population while designing new schemes development projects.

\section{References}

[1] Negarit Gazeta (2007). Solid waste management proclamation, Addis Ababa, Ethiopia.

[2] Haab, T. C. and K. E McConnell (2002). Valuing Environmental and Natural Resources: The Economics of Non- Market Valuation, New Horizon in Environmental Economics, Printed and Bounded in Great Britain by MPG books Ltd, Bondman, and Cornwall. 
[3] UN-GLAAS (2017). Financing universal water, sanitation and hygiene under the SDGs: Global Analysis and Assessment of Sanitation and Drinking-Water, Geneva.

[4] Kothari, C. R. (2009). Quantitative Techniques, 9th ed., New Delhi: Vikas Publishing House Pvt. Ltd.

[5] Verbeek M. (2004). A Guide to Modern Econometrics. 2nd. ed. John Wiley and Sons Ltd., England.

[6] Green. W. H. (2011). Econometric Analysis, New York, Macmillan Publishing Company.

[7] Muhdin M. (2016). Journal of Environment and Earth Science ISSN 2224-3216 (Paper) ISSN 2225-0948 (Online) Vol. 6, No. 7.
[8] Birhanu Y. and Berisa G. (2015). Assessment of Solid Waste Management Practices and the Role of Public Participation in Jigjiga Town, Somali Regional State, Ethiopia. International Journal of Environmental Protection and Policy. Vol. 3, No. 5, 2015, pp. 153-168.

[9] Aklilu A. (2002). Households' willingness to pay for improved solid waste management: the case of Addis Ababa.

[10] FAO (2017). Corporate Documents Repository: Application of Contingent Valuation Method in Developing Countries - PDF notes: http://www/fao org /DECREP/003/X8955E03.htm. 